\title{
SONGS FOR CHILDREN
}

MRS R.B. TRITTON

No $8, T H E$ DOG \& THE COW.

MUSIC BY

MRS J. WORTHINGTON BLISS

(MISS LINDSAY)

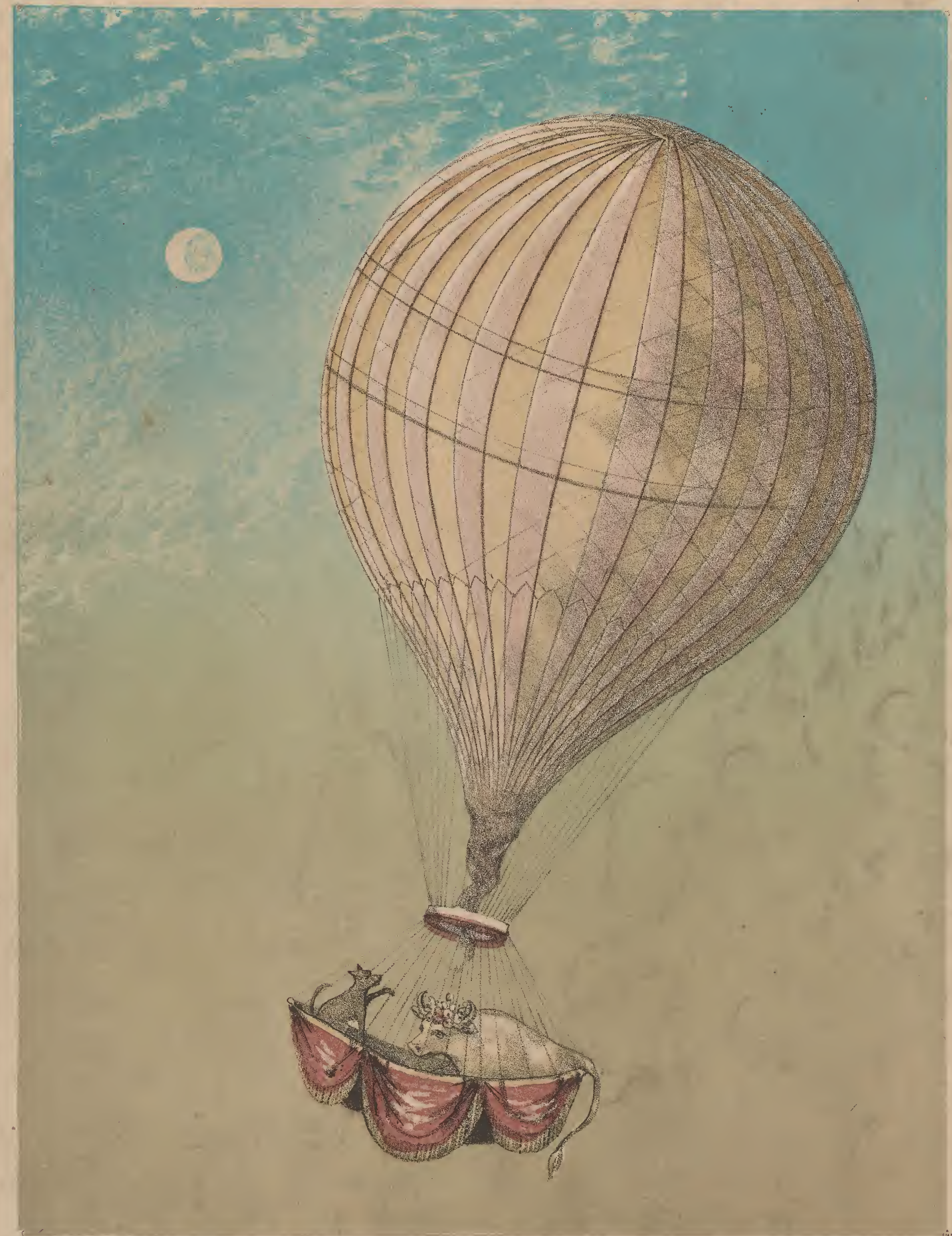

Ent. Sita. Hall.

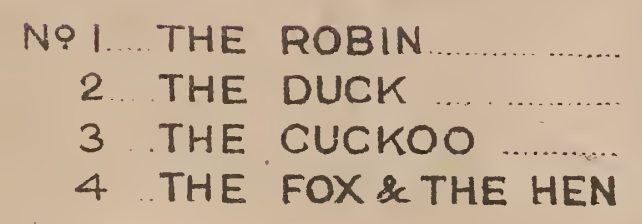

N.5. THE OWL \& THE PUSSY-CAT

6 MRS BLUEBOTTLE FLY

7...THE DUCK \& THE KANGAROO

8. THE DOG \& THE COW.

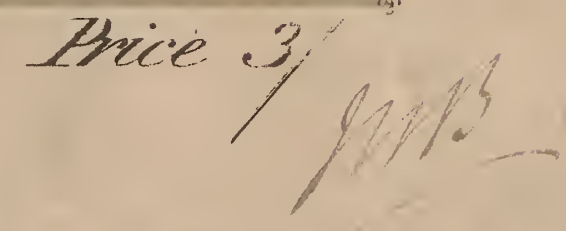

LONDON: J. B. CRAMER, \& CO 20I, REGENT ST W 


\section{THE DOB AND TAE BOW.}

THE WORDS BY

MRS. J.WORTHINGTON BLISS.

MRS.R.B. TRITTON.

(MISS LINDSAY.

Con spirito.

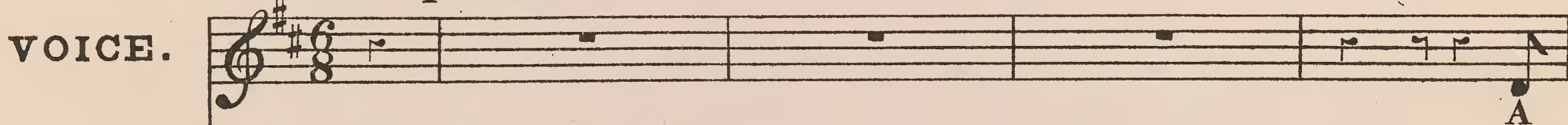

PIANO.
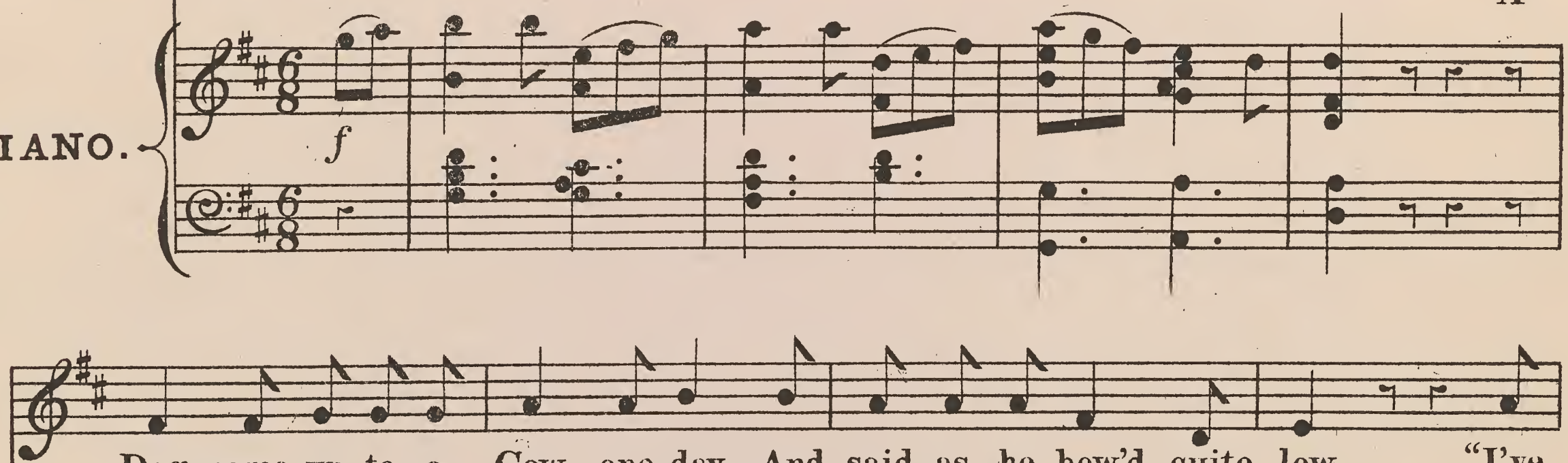

Dog came up to a Cow one day, And said as he bow'd quite low- "I've

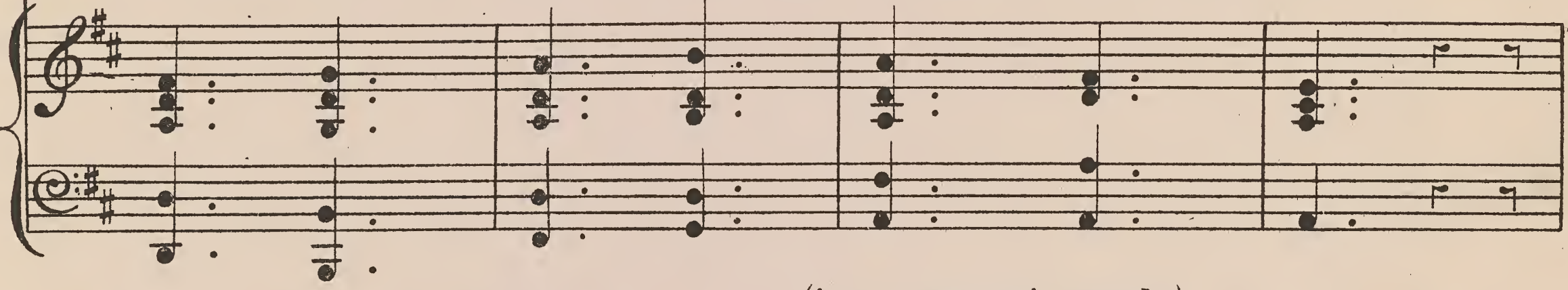

(in a persuasive style.)
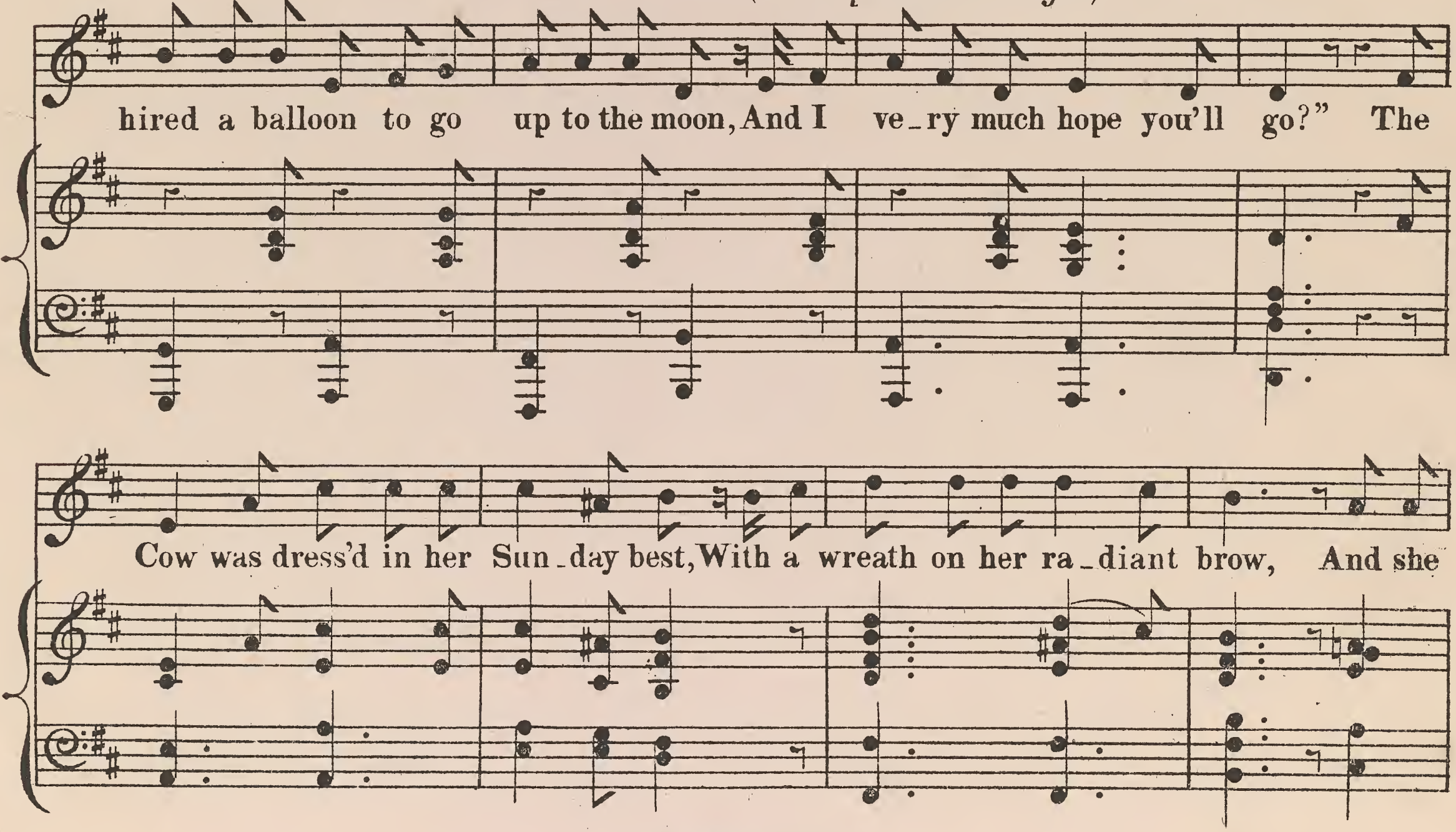

(J.B.C\&CO 8+91) 
2

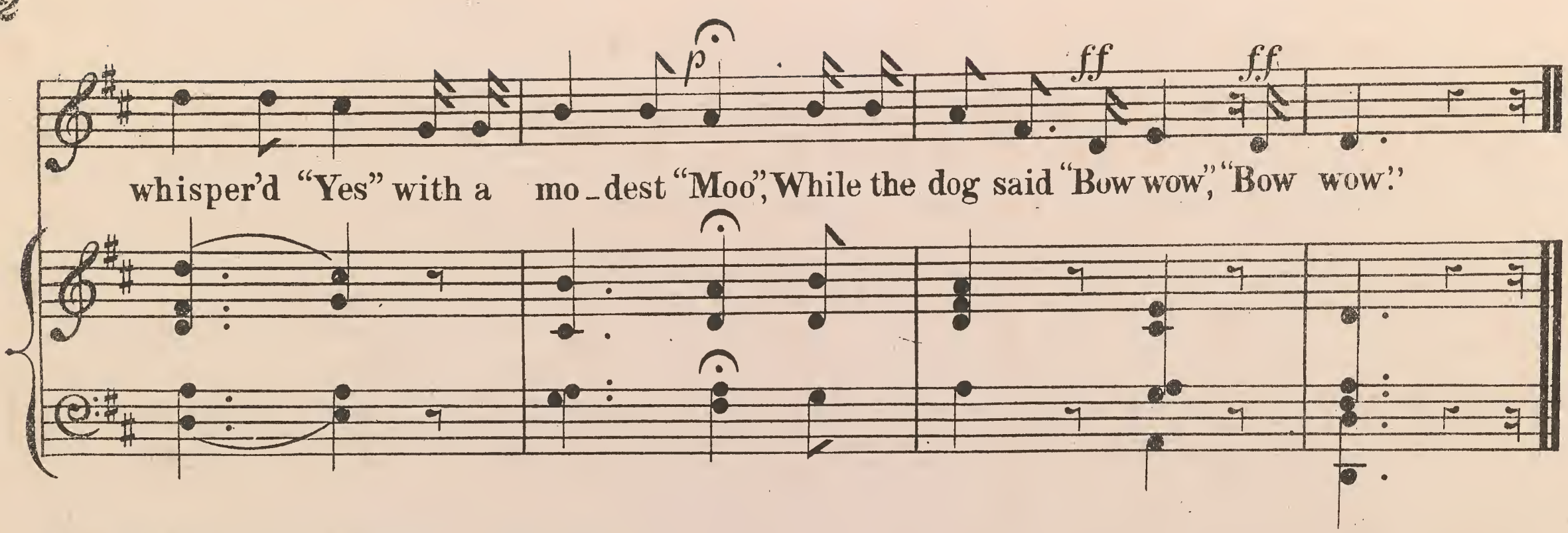

CHORUS for Children. (Optional.)
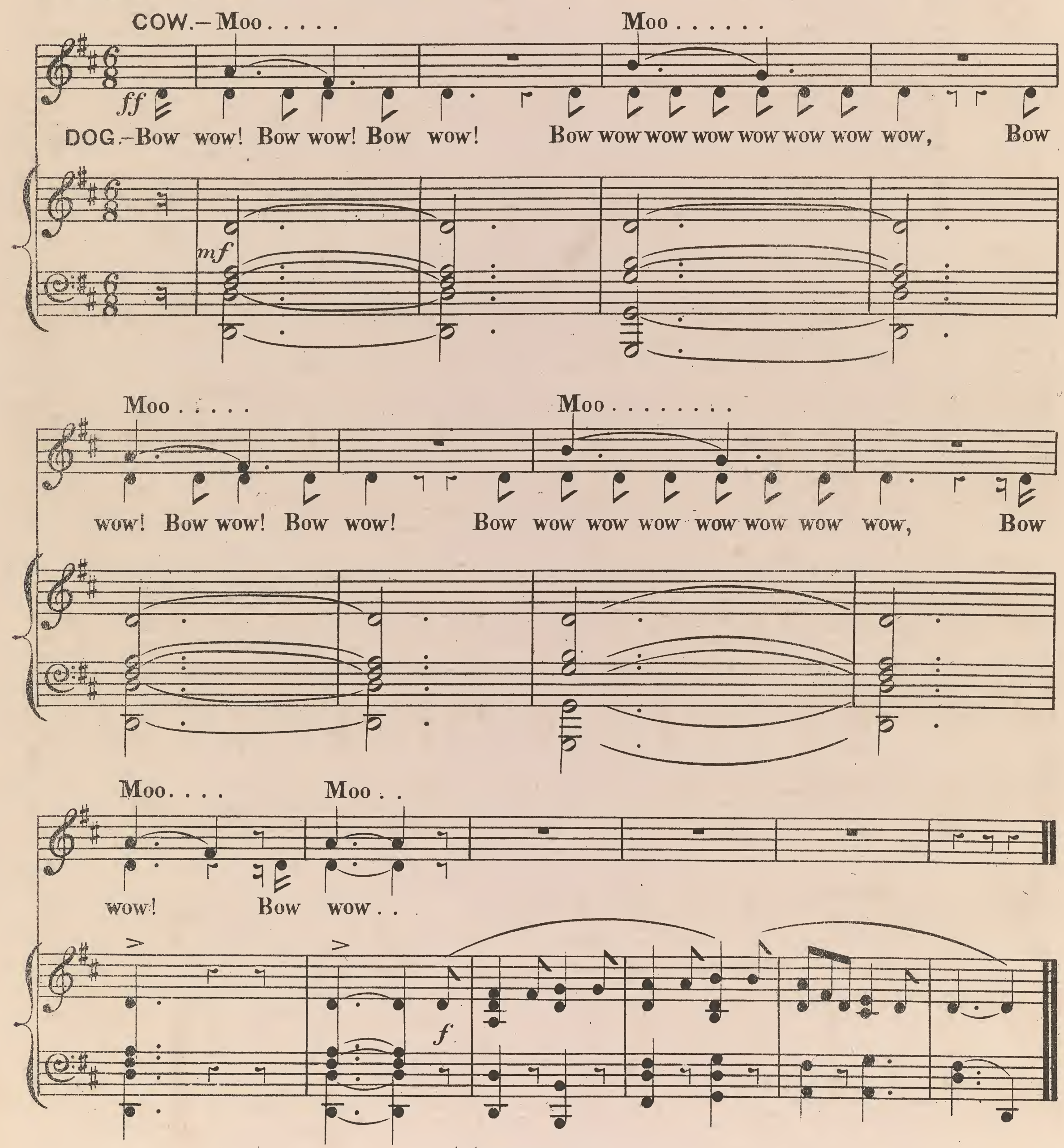

(J'B.C\&CO 8491) 
2ND. VERSE.

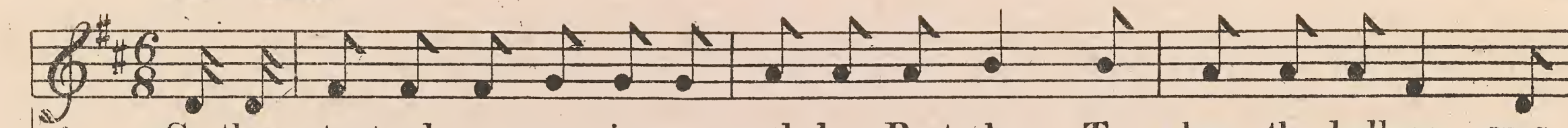

So they start_ed a_way in a, yel_low Post-shay To where the balloon was
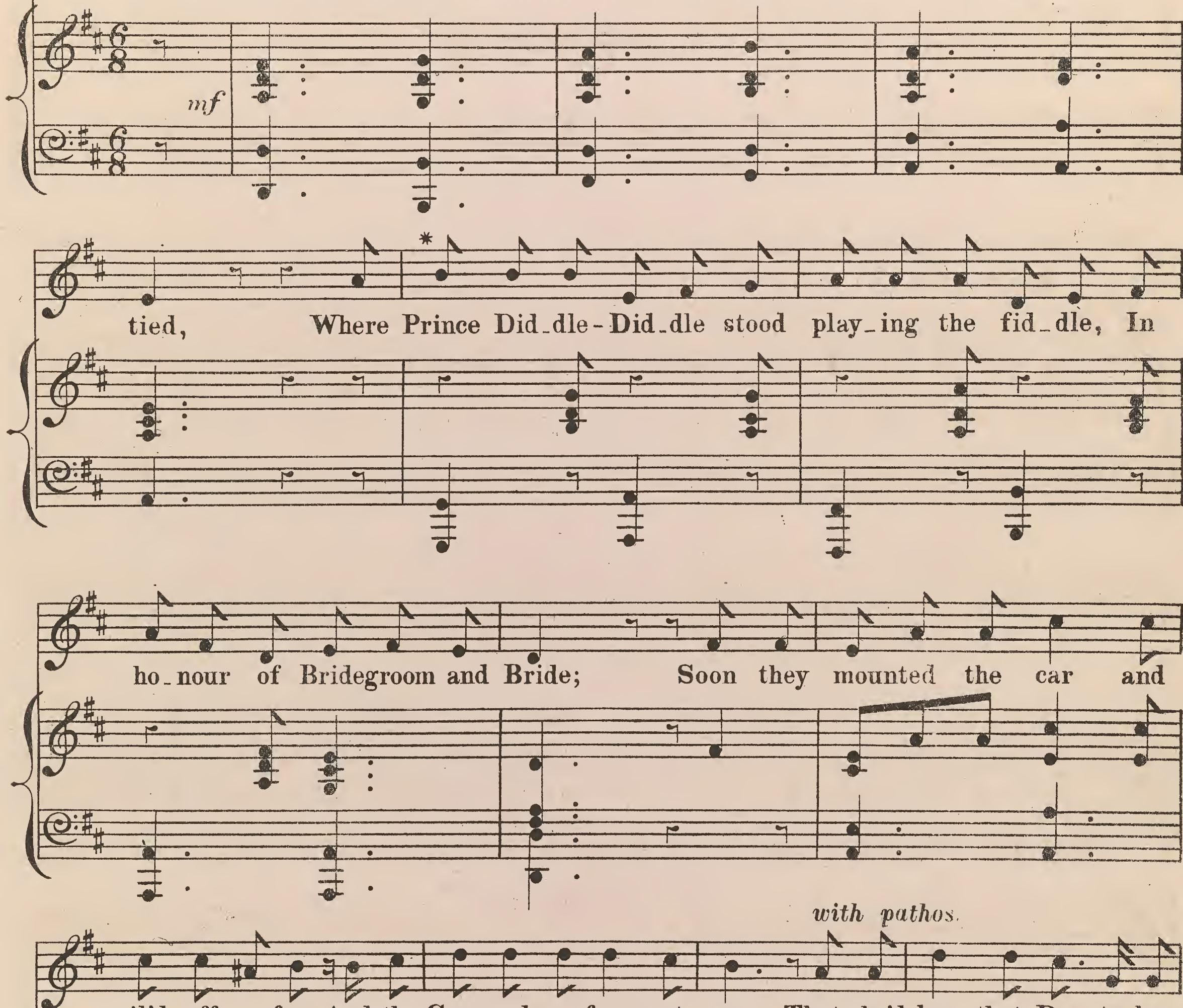
sail'd off a_far, And the Cow made a fer_vent vow, That she'd love that Dog to her
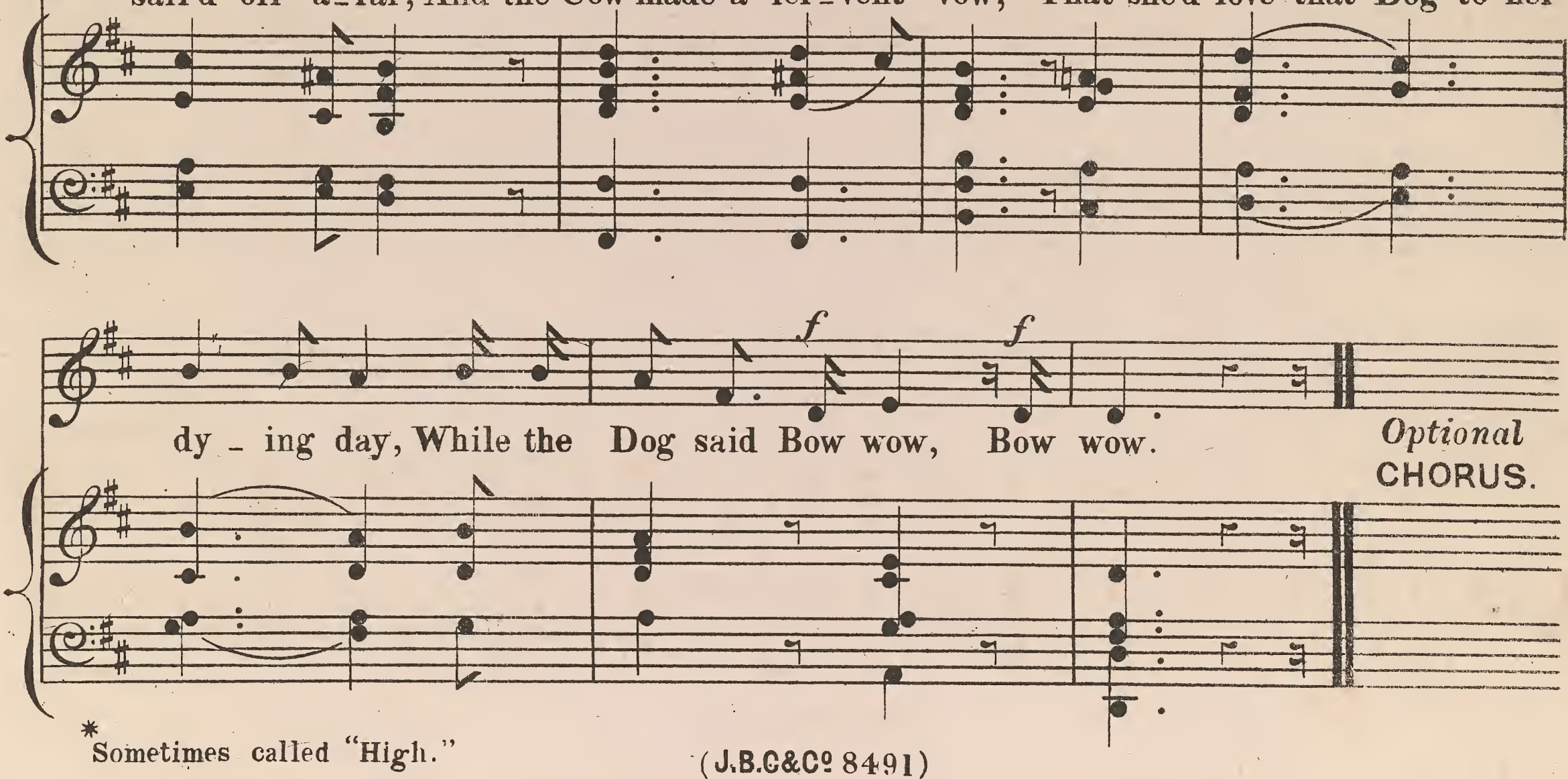
4

3RD. VERSE.
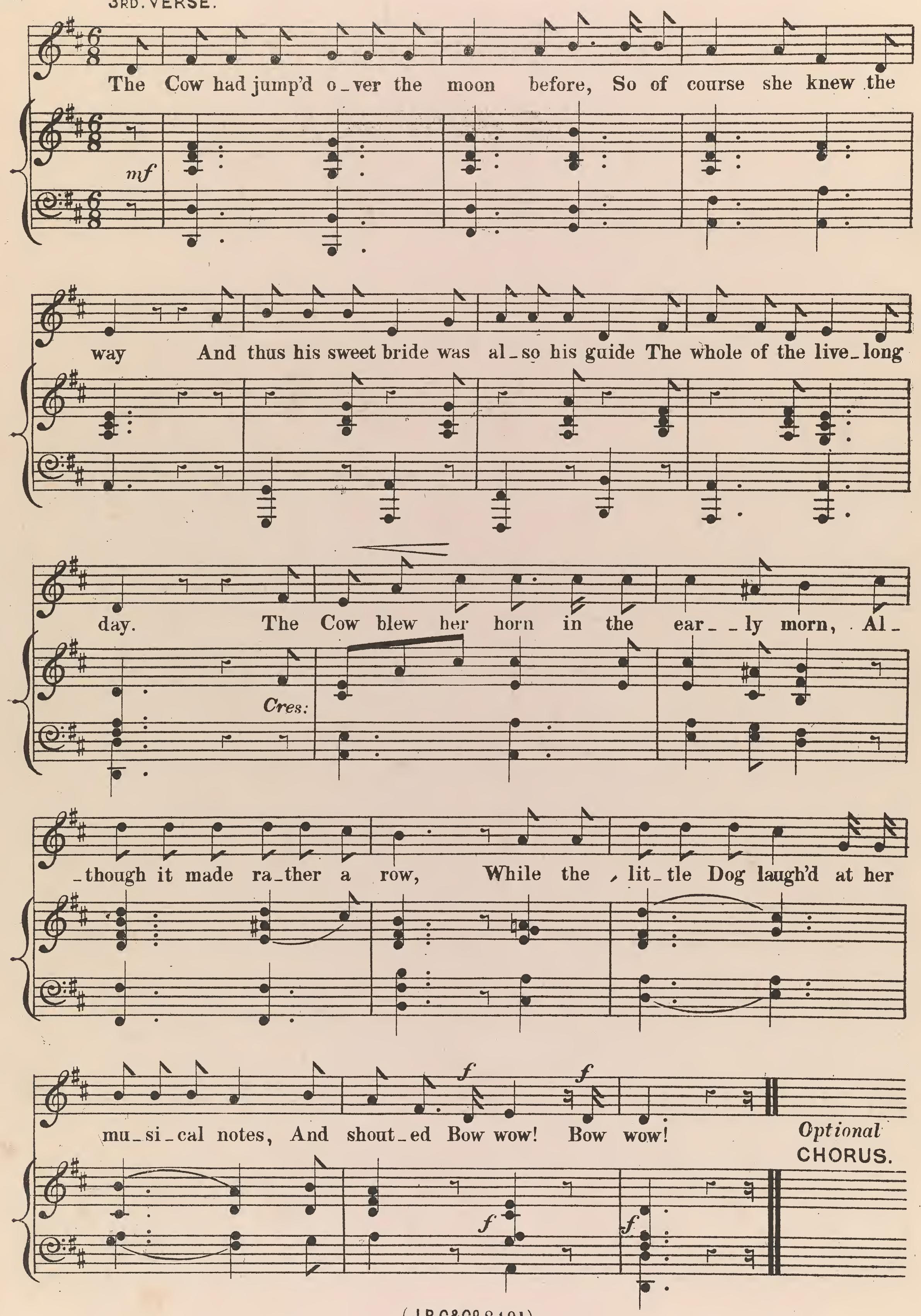

(J.B.C\&CO 81.91$)$ 
4TH. VERSE


(J.B.C\&CO 8491) 


\section{NEW AND POPULAR SONGS}

courfosis BX

\section{H. R. MARRIOTT.}

TITLE.

Fair Ellen of the Mill . Hidden Flowers . . . . Soprano or Tenor IVY • • . . . . • • . . . Soprano or Tenor I DReam of Thee Still • . - Soprano or Tenor Jack's Bequest •. • • • • Soprano Last Word at the Gate (The) • Soprano My Ella . . . . . . . . Tenor My Constant Lass . . . . . Tenor Old, Old Mill (The) • • • Con. or Baritone O Chide Me not for Loving - Mezzo Soprano REST (Charming Ballad) . . . . Soprano or Tenor Song of the Flower Maiden - Sop. or Mez. Sop. Sweet Rosabelle . . . . . Tenor There is a time WHEN ALL IS BRIGHT

Thy FACE (Fiftieth Thousand) . . . Soprano or Tenor

\section{DitTo.}

Thinking Love of Thee • . Soprano or Tenor Thou art My Star . . . . Soprano or Tenor Where Nightingales Sing • · Soprano or Tenor We MeEt Again (Sequel to "Thy Face") Soprano or Tenor Come Again, Sineet Dream • • Duet, Sop.\& Con. Old Love . . . . . . Duet, Sop. \& Con. Welcome Home... . . . Vocal $\underset{\text { Solo }}{\text { Quartet }}$ or

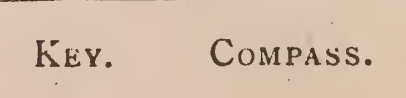

AUTHOR.

PRICE.

C E to F Miss Kate Loud $4 s$.

B flat $\mathrm{E}$ to $\mathrm{F}$ H. B. Farnie $4 s$.

I) $\begin{gathered}\text { C to to } \\ \text { Hsharp B. Farnie } 4\end{gathered}$

F D to F G. T. Newbury $4 s$.

$\mathrm{D} \mathrm{D}$ to $\mathrm{F}$ Edward Oxenford $4 s$.

F C to $F$ Miss Clara Loud $4 s$.

G D to G. W. Glenistrik $4 s$. B flat D to $\mathrm{F}$ Edward Oxenford $4 s$. D A to D Miss Clara Loud $4 s$. $\mathrm{F}$ D to F L. M. Thornton $4 s$. $\mathrm{F}$ C tô $\mathrm{F}$ R. A. Lejoindre $4 s$. D E E to Miss Clara Loud $4 s$. F D to G C. Featherstone $4 s$. E hlat D to F Miss Clara Loud 45 D D to G R. A. LeJolndRe $4 s$. C C to F R. A. Lejolndre $4 S$. G D to G R. A. Lejoindre $4 s$. F C to F Edward Oxenford $4 s$. $\mathrm{F}$ E to $\mathrm{F}$ F.DWARd OXenford $4 s$. F C to F R A. LejoIndre 4 s. F Mius Clara loud $44^{s}$. F H. B. FARNIE $4 s$. D IV. Glenister $4 s$. N.B.-In specifying the Compass of a Song, the lowest note is the one named first.

LONDON: J. B. CRAMER AND C0., 201, IEGENT STREET, W. All the above Songs Half-price and Post Free. 


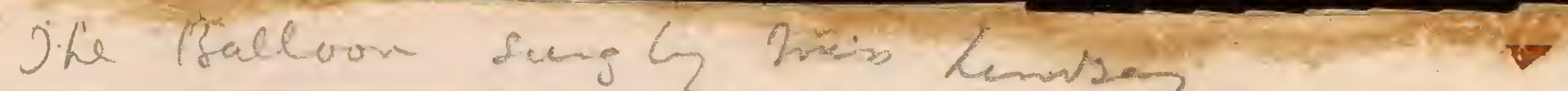

(MISS LINDSAY)

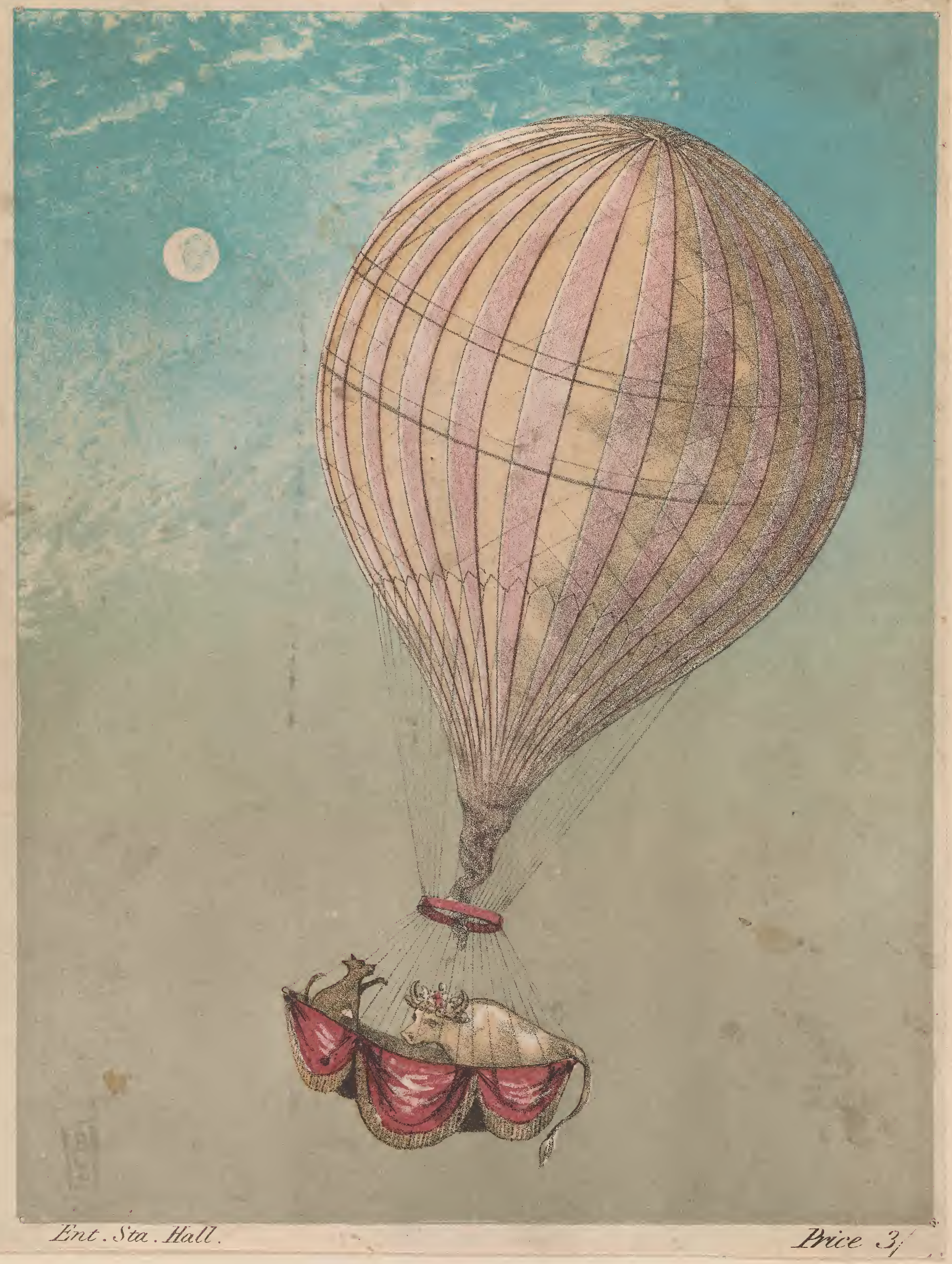

ca 1860 
